\title{
Strengthening of the Territorial Position of Valladolid through Planning Strategies: Networks, Patterns and Centralities
}

Juan Luis de las Rivas Sanz and Mario Paris

School of Architecture, Universidad de Valladolid, Valladolid 47011, Spain

\begin{abstract}
The urban condition of the European territory requires new approaches to explain the current development of cities and to propose new planning tools. The aim of this paper is to demonstrate that we can support an innovative perspective based on intermediate geographical scales, more useful for outlining the specific features of territory. While we analyze the territory, we should overcome the strictly local scale of the administrative boundaries and create new relationship between contemporary urban concepts (metropolization of territory and metapolis) and the regional ecological patterns. In the case of Valladolid (E) urban/metropolitan area, we focus on both causes and process of city growth. We have understood that it could be inefficient for planning forgetting the real spatial configuration (the city is located in an intersection between two territorial corridors) and misunderstanding the territorial role of the city at different scales (the double centrality in the emerging urban area and in the region). The significance of this case is to reveal the inter-scalar condition of places as generators of constraints in the contemporary urban fabric and, at the same time, to show the quality and the potential of places in the future urban realm.
\end{abstract}

Key words: Urban planning, town planning, city-region, urban networks, centralities, green corridors.

\section{Introduction}

The administrative model and its subdivisions (European Union, Nation, Region-Comunidad Autonoma in Spain, NUTS (nomenclature of territorial units for statistics) for EU-County and Municipality) create the basis for the interpretation of medium cities' territorial role. At the same time, those subdivisions are the support of the statistical analysis of space. But contemporary urban conditions, as several scholars as Garreau [1], Ascher [2], Monclús [3], Graham and Marvin [4], Amin and Thrift [5], Nello [6], Bagnasco [7], Indovina [8], Portas et al. [9] highlight through different points of view, they exceed those boundaries and their current complex configurations depend on adaptive logics to the place and to other geographical, social and economic

Corresponding author: Mario Paris, Ph.D., architect, research fields: interpretation of urban and territorial complex phenomena through factorial analysis and statistical models. E-mail:mario@institutourbanistica.com. conditions. In medium cities, those supra-local tensions overcome the township or county administrative limits and they are visible only at regional scale. At the same time, the conventional regional scale is not useful to explain most of the causes of those dynamics.

The aim of this paper is to demonstrate that we need new approaches, based both on intermediate geographical scales and on the specific features of territory, to explain urban phenomena in medium cities. These new approaches should overcome the strictly local scale and most of the administrative boundaries. To achieve this explanation, we have to relate the contemporary urban concepts with the regional ecological pattern. This operation could show us the concrete places and the specific conditions of contemporary urban development.

The sample of Valladolid is useful to understand this approach. Along the first part of the essay we will present some features of the city, its spatial 
configuration and its territorial role. In the second part, we will describe the conditions and the constraints of this situation. We will focus on both causes and process of city growth. They are also relevant for understanding the identity of the city. At the same time, they represent potentially concrete opportunities for future urban development.

\section{An Emerging Metropolitan Area: The City of Valladolid}

Valladolid is the largest city in Castilla y León (2.5 million of inhabitants, 2011), a vast region (94,225 $\mathrm{km}^{2}$ ) located in the centre of the continental Spanish plateau. Several factors characterize the location of the city:

- The confluence of three rivers: the Esgueva, the Pisuerga and the Duero. The growth of the city has occupied the valley;

- The cross of two important infrastructures: the A6, a motorway which flows from Madrid to Galicia and the E80, an important route for Europe on the path Lisbon-Helsinki, a really combined transport axis $^{1}$ as pointed by EU [10];

- The door role from Madrid: Valladolid connected with Madrid by the AVE (the Spanish high-speed railway), is the largest urban agglomeration in the north-west sector of Spain.

These factors determine the two profiles of the city: on one hand, Valladolid is a regional capital and, on the other hand, it is a modern industrial centre. According to EU [11] and De las Rivas [12], the city reflects these two characters because of its size and the nature of local economy, where a solid industrial sector (Renault, Michelin, agro-industrial activities, etc.) coexists with an important university and several research centres. That is, Valladolid occupies a strategic position in the north-west of Spain, and is one of the largest interior cities in the country. Both these two factors, one dimensional and the other

\footnotetext{
${ }^{1}$ According to EU [13], the axis would have to combine the
} Atlantic Railway Corridor and a motorway. positional, are the key to comprehend and to develop the city potential.

We proceed to explain the urban reality of Valladolid through two visions: the first one-conventional-focused on the administrative and material condition of the city and the other-innovative-related with the ecology of urban system and its role in the territory.

\subsection{The City from the Region: Valladolid on the Urban System of Castilla y León}

According to its population, Valladolid is the 13th city of Spain in size $(313,000$ inhabitants, 2011) and plays a central role in cities network of Castilla y León ${ }^{2}$. The regional territory is marked by a precise correspondence between the geomorphology (mountains, riverbanks and central plains) and the localization of major urban centres. As De las Rivas [14] points out, Valladolid and the other three largest cities of this system, León, Burgos and Salamanca, shape a virtual tetrahedron which contains the most important nodes of the region and organize its central space.

The position of the city is central not only for reasons of position or size. It is the capital of the region (Fig. 1). The condition of well-located and well-connected space-both in the Comunidad Autonoma and in the Spanish peninsula-has favored the city and has grown over its historical development.

The size of the city, the role of capital, the presence of large industrial plants and, at the same time, the high level of quality of life (due to a high presence of services, educational and cultural functions, sports spaces, etc.) create in Valladolid the conditions of a rich and complex urban space. The services sector of the city, for example, attracts people from the rest of

\footnotetext{
${ }^{2}$ The capital status, although it is not defined by law, is a historical consequence: this city has been the capital in the past, with a strong administrative structure, and by objective circumstances: Valladolid is in the center of the region and is the largest city in the region.
} 
the own province and other close provinces over the urban area. More than $30 \%$ of the city's inhabitants were not born in Valladolid (Data: Instituto Nacional de Estadística, 2010) and the population has a high level of education. The city is simultaneously a centre for commercial activities for private services as well as logistical pole. Over the last decade, by taking advantage of its new features (i.e., the high speed railway), the city has been strengthening its economy and improving his profile of modern urban centre.

\subsection{Valladolid in Its Context: Geographical Logic and Intermediate Territories}

Several recent investigations point to a combination of different spatial phenomena (the functional dispersion in a more and more large territory, the increase of flows and activities in urban peripheries, the physical transformation of consolidated city or the urbanization of large peri-urban spaces among others) as the generator of a new urban environment. Indovina [8] called this process the "metropolisation of territory"3.

For recognizing all these transformations, we should consider the intermediate and unusual scale of these phenomena. That is a difficult task because it would be founded in a complex interaction of such a different factors and on the spatial result of this interaction. In this "territorial" way for understanding the city, we have to focus a new point of view, both innovative and careful, to the place rooted dynamics of an urban area that exceeds administrative boundaries for including both the city centre and the outskirts, with other little towns and villages around. In 2011, the municipality of Valladolid had 313,000 inhabitants, but to these it should be added the linked

\footnotetext{
${ }^{3}$ Without coordinate planning, this urban territory seems a big unfinished puzzle, where the complexity of land uses, their mixture and, in any cases, their banality look out of control. Only we can recognize a strategy of order in the infrastructural nets in their continuity and hierarchal basis. According to Secchi [15], this process is not just simple city growth dynamic but a real metamorphosis of territory, a "change of status" and Font [16] explains it as "the explosion of the city".
}

population of nearby towns (more or less 100,000 inhabitants, Data INE (Instituto Nacional Estadistica)). Finally, more than 410,000 inhabitants live in this urban cluster ${ }^{4}$, formed by 23 municipalities and a surface of $981 \mathrm{~km}^{2}$. The central city changes because the suburban area changes. This new urban dynamic takes place in rural periphery where, since barely 15 years, the localization process of industrial plants, public functions and residential areas ${ }^{5}$ had a punctual and spontaneous character. Definitely, we could define this transformation as a "complex activation process". Through this process, Valladolid is not just a city, but it is the centre of the 12th urban area in Spain and the first one in Castilla y León region. Nowadays De las Rivas et al. [17] prefer to define Valladolid, in comparison with other Spanish urban areas, as an "emerging urban area". The DOTVaEnt (Territorial guidelines for Valladolid and its outskirts) plan by De las Rivas [18] was the first regional planning work where we used this concept. Really, the urban growth exceeded Valladolid's boundaries in the 1980s involving only some of the closest townships: the result was called the "Valladolid's urban agglomeration". In the last decade of 20th century, the "city-effect" became more and more intense around the city: discontinuous traces of urban use of space were appearing in a larger territory beyond the city. Up to now in this area, it keeps growing a peri-urbanization process based on the moving of residential spaces but also of industrial functions and services from city centre to the surrounding municipalities. This unplanned independence between residence and work marks the space and, for this reason,

\footnotetext{
${ }^{4}$ The recent transformation of this area is extraordinary: in 1981, the other municipalities around the city lived 29,000 people and 330,000 inhabitants in the central city. Today, more than 100,000 people live in the outskirts of the central city, meanwhile this one keeps its population. Some of the towns contiguous to the city have grown, between 2001 and 2011, more than $250 \%$ (Data INE, 2011).

${ }^{5}$ There are several typologies of those residential groups: settlements marked by the irregular subdivision of land and propriety, neighborhoods for working class, developments of single family proprieties and secondary bourgeois residences.
} 


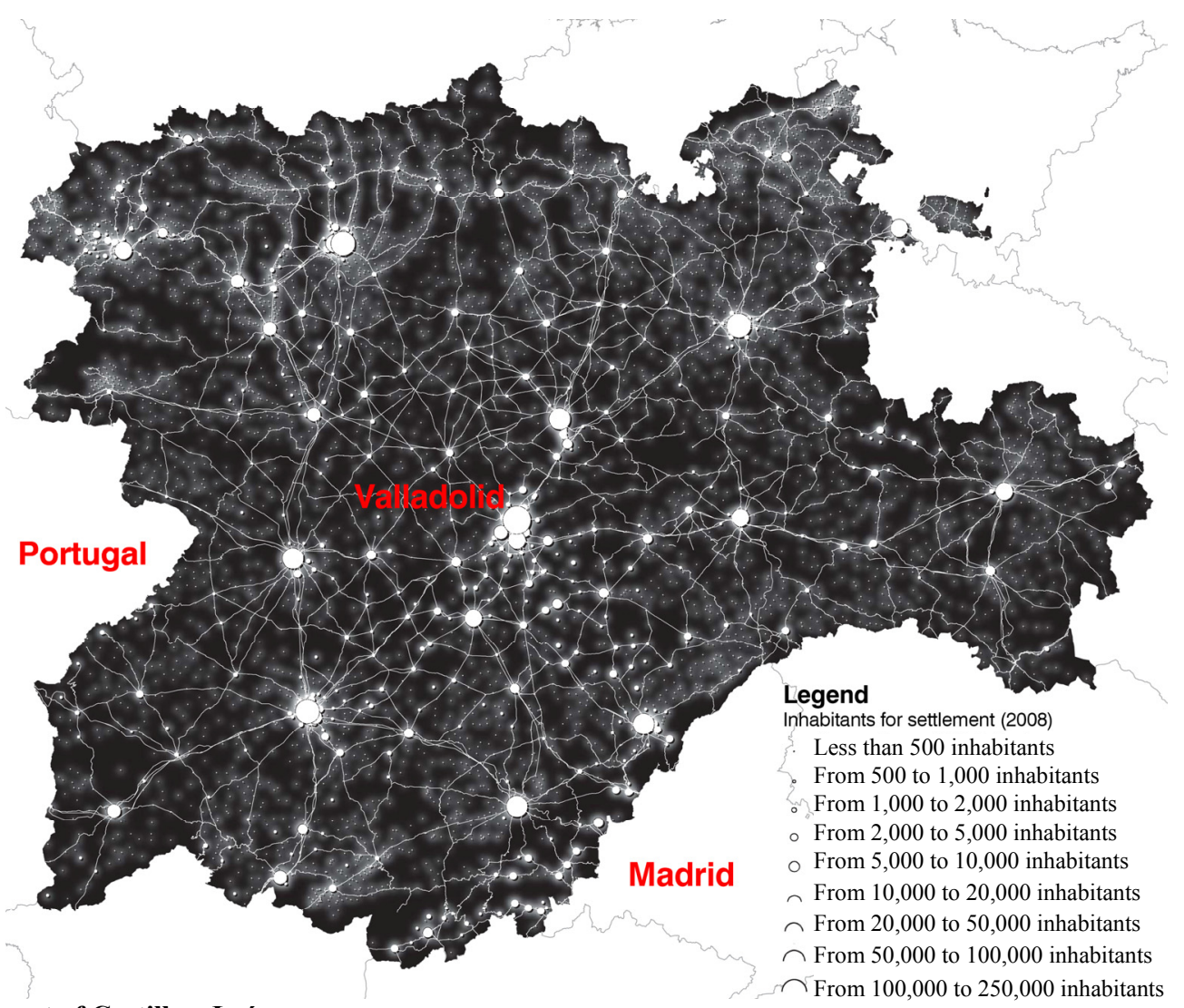

Fig. 1 Settlement of Castilla y León.

Source: IUU-University Institute of Urbanism.

we should interprete - as Ascher [2], territory as a whole as a basin of life and employment.

\section{Valladolid as a Cross of Two Dynamic Corridors}

According to the two visions proposed above, the complexity of urban dynamics is the result of adaptation logics to both geographic and economic conditions of a specific territory. Especially in medium cities, supra-local dynamics interfere the conventional dimension of municipalities or counties and appear at regional scale. At the same time, there are no clear explanations of the local transformation just using the regional scale on the analysis. For Valladolid, it is important to consider the double role of the city: first, the city is the centre of an urban area both different and complex, but it is also the result of the adaptation to specific characteristics of the regional context. But thinking in the territorial networks, Valladolid belongs to diverse and important territorial axes. The effects related to this condition of double centrality (urban and territorial) make different, larger and deeper the conventional urban transformations.

\subsection{The Industrial Corridor}

Tordesillas-Valladolid-Palencia: Singular Segment of International Transport Corridor (E-80)

According to Álvarez [19], in the Middle Ages, the corridor Tordesillas-Valladolid-Palencia (Fig. 2) had been an important territorial structure for both regional and urban development which strengthened its role today as combined transport axis [20]. The evidence of this role is the importance of the corridor for the infrastructural network ${ }^{6}$, for the demographic

${ }^{6}$ The old Canal of Castilla, the railway line, the high speed railway and the motorway run parallel in the valley of Pisuerga. This is an intermodal corridor, where the most important 
dynamics $^{7}$ and industry ${ }^{8}$. The co-presence of these three complementary realities is one of the explanations of the corridor potential as attractor of functions, transformations and investments. Over the last years, economic activities moved towards the urban periphery and especially over the corridor: logistics, industries-basically in industrial parks-but also shopping mall, retail in general and some tertiary functions. Actually, this movement cannot consolidate new and complex spaces of centrality probably for one reason: the corridor has not yet attracted significant residential spaces outside of urban areas of Valladolid and Palencia 9 .

In spite of the fragility of the metropolitan structure of Valladolid, its growth extends its influence as a result of the occupation of a larger and larger area, the reduction of the global density and the introduction of uncertain expectations of urbanization. The Valladolid's urban agglomeration tends to discontinuity, with fragments and gaps inside and without clear limits or edges. Obviously, the contrast between the solid inner city and the broken tissue of the suburb is an immanent character of the area. In this situation, one of the conditions that influence the development is the accessibility provided by the corridor.

In other words, the corridor Valladolid-Palencia has an important role for the transportation (regional and supra-regional scale) but is also a metropolitan axis that consolidates the existent centralities in its

infrastructures are the E-80, international route which connects Portugal with France and Europe and the HS railway [21].

${ }^{7}$ The two urban areas of Valladolid and Palencia concentrate the largest part of the population of both province. In the middle of the corridor, there is a clear demographic court, marked by a low spatial density $\left(<25\right.$ inhabitants $\left./ \mathrm{km}^{2}\right)$ and with the character of an rural area.

${ }^{8}$ Mapping the first 200 main industries of Castilla y León (Data CyL Económica [22]), the corridor emerges as the major industrial spaces of the region.

${ }^{9}$ There was a "centrifugal dynamic" for the inhabitants of the two cities towards the closest townships of the urban area. The reason is the change on the residential needs: young couples normally move to the suburb searching cheaper and larger houses than those present in the central city. The result was the transformation of the hinterland of the two cities [11]. extremes. The corridor does not create an absolute continuity of the urban along its route. For this reason, the corridor is not the "axis" of a conurbation, but it is an infrastructure which strength, the urban areas of Valladolid and Palencia and makes possible "scattered episodes of centrality". The rest of the territory within the corridor remains an intermediate landscape, both diverse and interesting which, outside of the corridor, disappears.

\subsection{The Duero's Corridor, an Exceptional Wine Space}

Valladolid and its metropolitan area are the midpoint of the Duero's corridor. This is another territorial structure which, with an east-west axis, interconnects valuable spaces and cities, shaping a singular landscape with great potential. According to the Castilla y León Regional Council [23], the Duero's corridor could be an axis for balanced attractive, competitive and exemplary development, thanks to the identification created between the regional space and the river's basin ${ }^{10}$.

The signals of the territorial, economic and strategic importance of the river are evident in many areas, including agriculture, energy production, preservation of environmental and cultural values, with the adaptation of traditional economies to the processes of innovation and technological development. Among others, the wine production reflects the extraordinary character of this space, which has its apex in the territory of Valladolid. The high quality of production and landscapes speaks of a deep connection between natural and productive spaces, residence, tourism and cultural heritage. The morphology and the hydrology (physical support), the vegetation, the infrastructure and the human settlement, all of them create a space with a strong territorial identity, visible over the history and now, in landscape. The Duero River creates

\footnotetext{
${ }^{10}$ Over $95 \%$ of the Spanish territory of the basin of Duero is located in Castilla y León. The river flows over five of nine provinces before passing in Portugal. More than 800,000 inhabitants (Data INE, 2012) live in the 594 municipality $\left(25,100 \mathrm{~km}^{2}\right)$ of the river's basin. Among them, 108 are riparian, directly in contact with the river.
} 


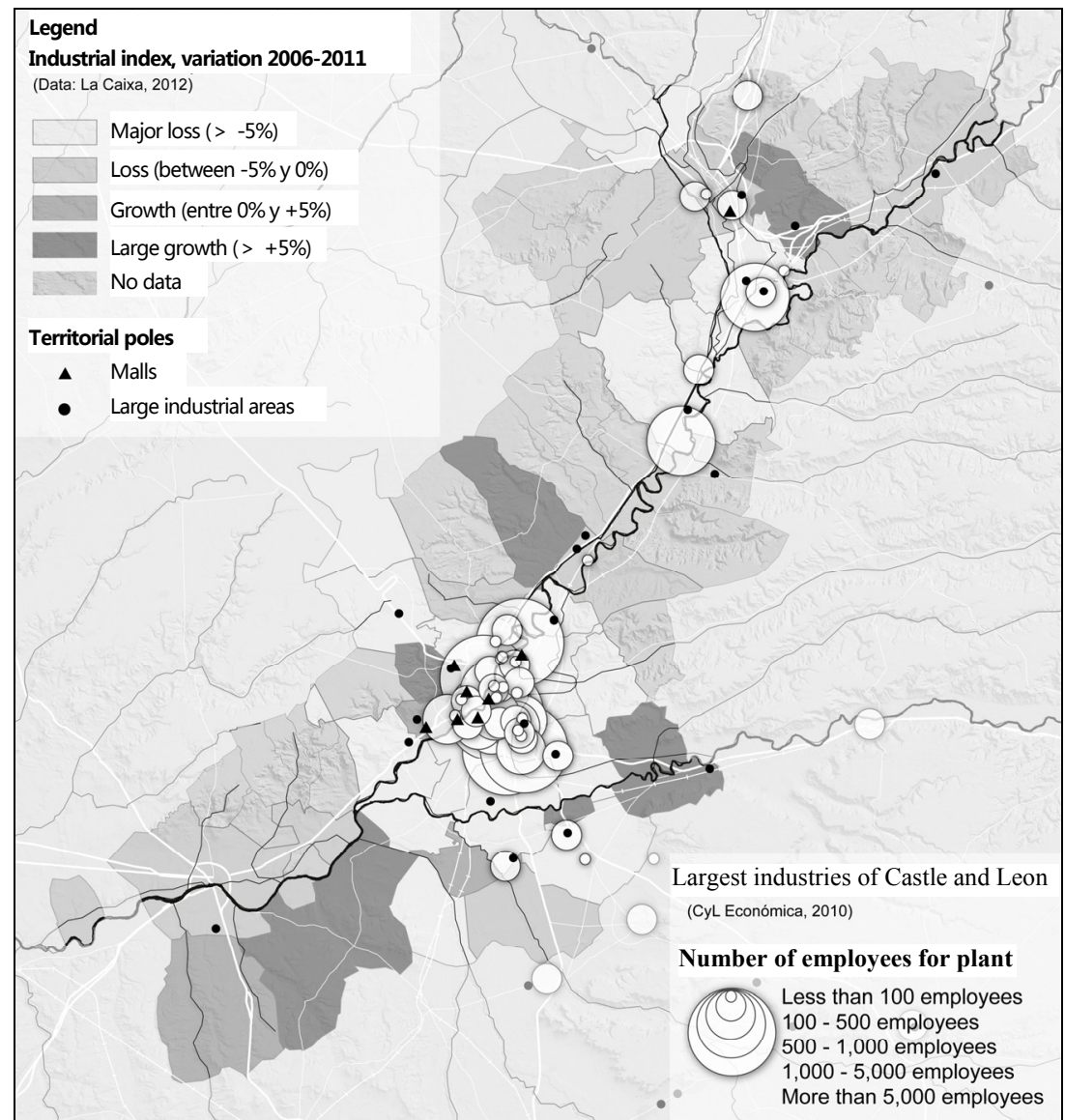

Fig. 2 Corridor Valladolid-Palencia. The main industrial spaces of the region.

Source: IUU-University Institute of Urbanism.

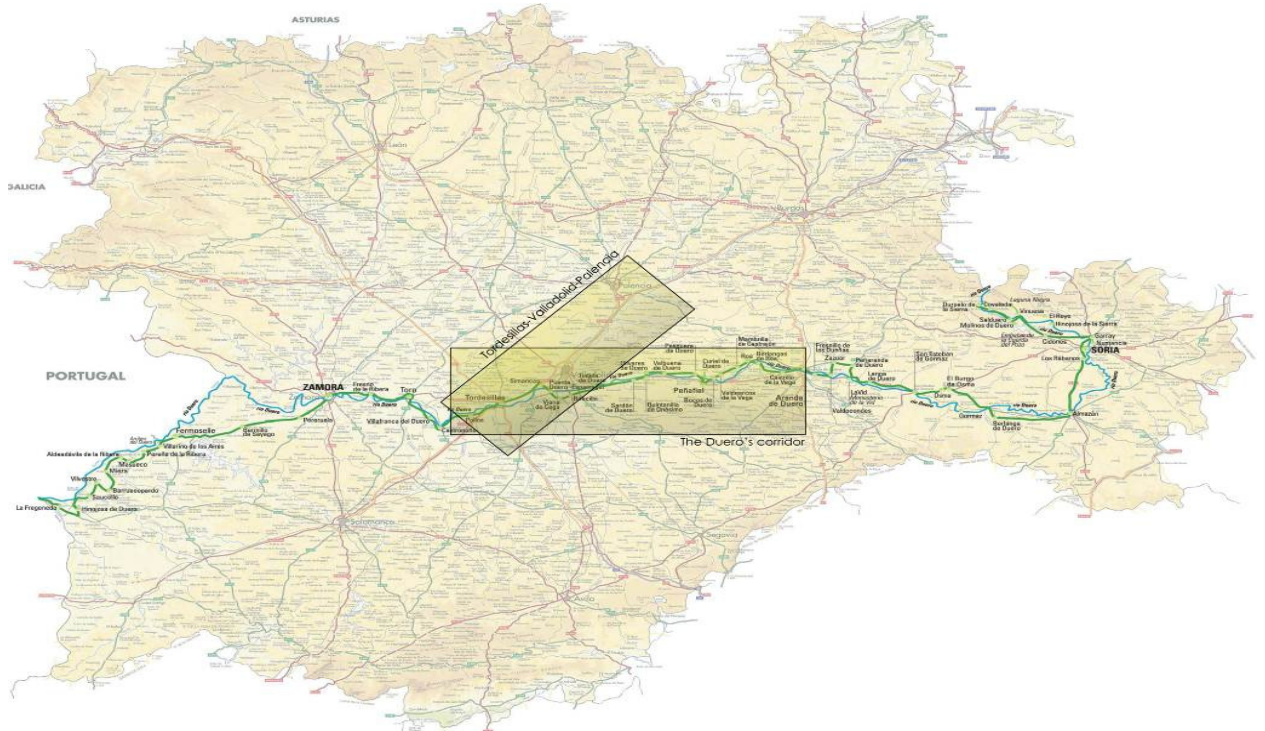

Fig. 3 Valladolid in the crossing of two dynamic corridors.

Source: IUU-University Institute of Urbanism.

this identity, relates large spaces, crosses provincial and state boundaries, and imposes a new territorial reference linked to its basin.

The superposition of the effect of the two corridors 
is visible at different scales (Fig. 3). To understand it, especially in Valladolid, we have to leave the city dimension and switch to a sub-regional scale: something different from the administrative or statistical approach. Several consolidate relationships and opportunities coexist in this space. Outside of this area, there is the rural territory, with its problems: the human depopulation, the search for an identity, the relation between urban and rural. Considering all these aspects, it is the first step to build both a believable and strategic vision, coherent with the future city-region.

\section{Towards a Coherent and Closer Interpretation of the Territory: Recognizing and Planning the Structure of the Valladolid Urban Area}

The aim of this essay is to interpret, both effective and integrated, those spaces that configure the urban agglomeration of Valladolid and its suburbs. We have been working over the last years in two planning systems: the local plan of Valladolid and the guidelines for its "emergent" metropolitan area ${ }^{11}$. For this reason, we focus on the main conditioners of its recent urban development and we highlight both the evolution and the consolidated tendencies of this process. So we related the factors exposed above with the ecological structure of the region, this operation allows us to detect both the localization trends and the development conditions in the area related with the urban process (its concrete places). There is an essential relation between the territorial constraints (physical, economical, etc.) and its spatial transformations. For Valladolid, we have considered the stability of its three principal patterns: the geographical location of the city, the infrastructure

\footnotetext{
${ }^{11}$ The most important result of our work is a new approach toward the territory of Valladolid urban area. We use it in the new local plan (we are still working on it) and in other planning works (DOTVaEnt, DOTCyL, etc.). This new approach allows a combination of strategies and decisions that promotes the reflection on this territory and the constant improvement of its space, towards both a more sustainable and integrated pattern.
}

networks - both actual and future, and the emergence of new phenomena related to the centrality.

\subsection{The Place, the "Solar Vallisoletano"}

The transformations of Valladolid and its urban area have been rooted, as García [24] said, into the characteristics of the solar vallisoletano, the geographical "genius loci" where the city is located, a unique space in the landscapes of the meseta, the Spanish internal plateau. The morphology of the place is the base for the economy and living in Valladolid, its settlements, corridors and land uses. These historical cross of rivers and infrastructures are the substrate for a humanized landscape, marked by the topography, the vegetation and the soil qualities. Despite of the large urban transformation over the last 50 years-several times completed with such a brutality in terms of physical space, the urban life and the economic activities keep close related with this landscape (the project of the "two ring park system"). In Valladolid, the urban makes a complex mosaic [25, 26 with the no urban where the physical continuity of the city $^{12}$ in more or less intense, and the rural is hided or mixed to this urban tissue [27]. The result is a structure marked by a system of countless small urban polarities.

\subsection{Fluxes: Interaction between the Urban and the} Networks of Infrastructure

On the urban area of Valladolid passes the road section which supports the most intense traffic flows of Castilla y León (a considerable percentage of this traffic is international). In spite of this importance, the city has a concentric double network of the

\footnotetext{
${ }^{12}$ The urbanization pressure, initially concentrated in the city, has been deployed in the suburban area and now sets a complex mosaic of land uses: depending on the proximity of watercourses (riverbanks), the existence of views (slopes) and the existence of large areas of woodland (pinewood). The immanent feature of all these places is the accessibility from the capital through its network of arterial or main roads. For this reason, the vast countryside south, occupied by pine forests, fields, river banks and with greater road density, has been the most valuable space in the urbanization process.
} 
infrastructure designed in the last 1970 s, today in the last phase of construction.

The mobility systems, characteristic of the contemporary urban areas, make possible different degrees of accessibility, without giving up on the increasing demand of complex and expensive networks. Based on resilience concepts, the mobility management should develop a more efficient public transport system. This is possible only if we could administrate the urban density as a strategy to make it efficient (the "city doors" project).

The shape of the future city may well correspond to the complementary development of local ecologies and infrastructures, where the urban fabric, in spite of the landscape discontinuity, cannot remain isolated: it has to be built into this landscape.

\subsection{New and Old Centralities}

Traditionally, the structure of Valladolid has been monocentric and its historic core concentrated all centralities, both real and potential. The urban planning supported this dynamic, which did not facilitate the spread of centralities to consolidate a polycentric pattern, more coherent with the urban reality (Fig. 4). However, this process grew spontaneously-something normal in the metropolisation processes, and it created new spaces of centrality (the new regional centralities project) [28, 29].

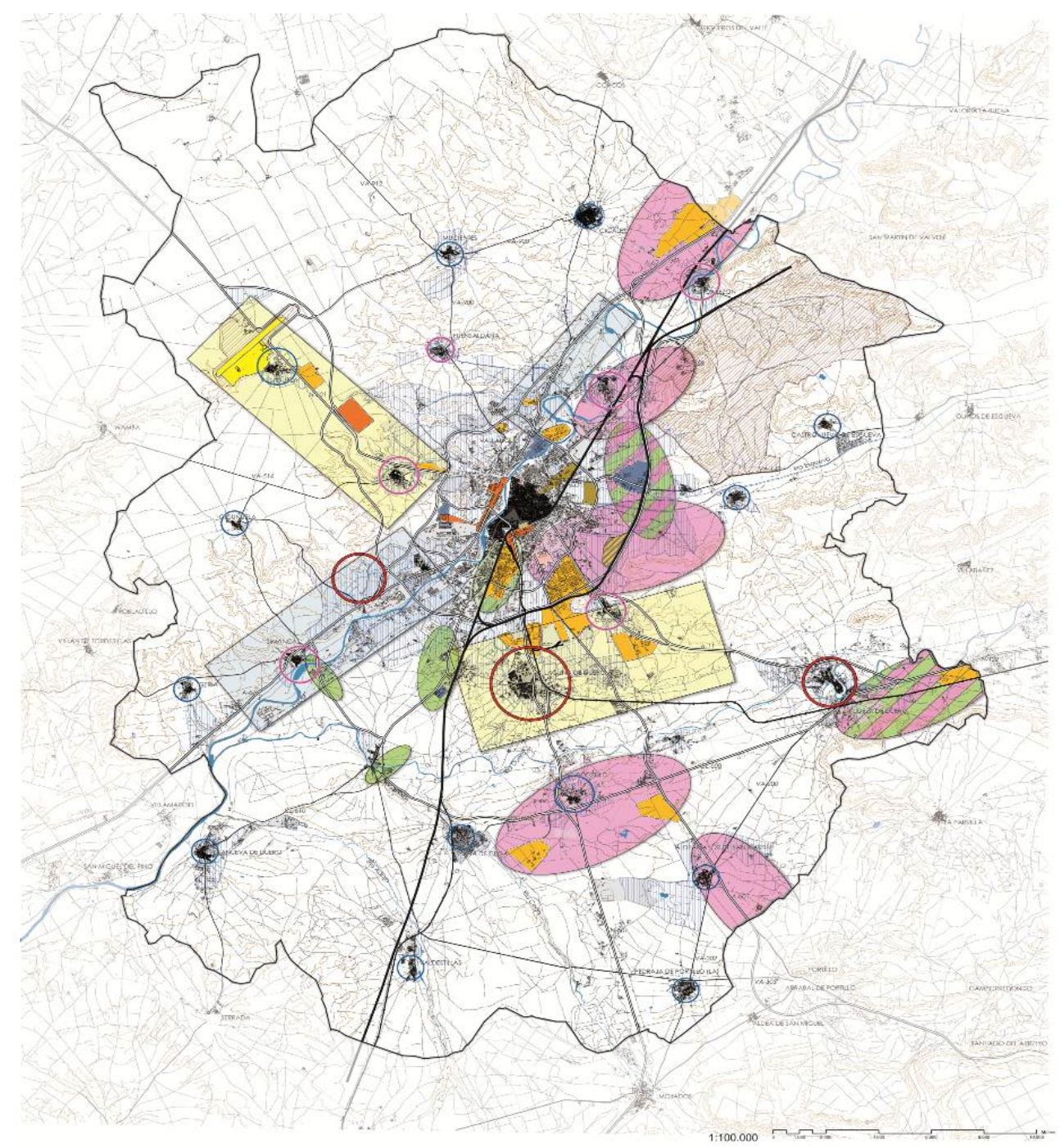

Fig. 4 Valladolid and its urban area: centralities and poles. Source: IUU-University Institute of Urbanism. 
Two of them are within the city (Avenida de Salamanca as large new axis attractor of central functions and the university campus). At the same time, there are same external polarities in areas characterized by a high degree of accessibility particularly towards the Boecillo Technology Park, the Villanubla Airport and the IKEA-Rio Shopping Mall: those are the potential places of centrality or new superplaces of the urban area.

\section{Results and Discussions}

This paper resumes several concepts created in the Instituto Universitario de Urbanistica [30] research group about regional and urban interferences in the definition of planning targets. This is not only a theoretical task. Working in Valladolid city-region plan (metropolitan scale) [31] and also in Valladolid local plan (urban scale) [32], we question spatial limits and targets of planning. This effort is useful for a deeper understanding of the "sense of place" which passes through the creation of new figures. The result is a new way to show the structure of this territory, more coherent with a contemporary narrative of space, and closer to the spatial and temporal dimensions of our urban-rural territory. Those figures are the base of a dynamic imaginary of our city and of our territory, but this new representation is not a real result, it is only the needful tool to know and plan on complex urban space.

In this work, we study the Valladolid's structure as a physical support-formal, functional and symbolic — of its emerging urban area, and we split up the "articulated geometry" of an unconventional representation of its urban and territorial structure. It corresponds to the mayor "groups of relationships" that structure the manifold and mediated urban reality: flows, activities, and local ecologies [33].

\section{Conclusions}

In this attempt for demonstrating how the local dimension could be strategic, the place conditions appear in the roots of the current urban dynamics, crossing boundaries and connecting different scales. The case of Valladolid is important to demonstrate who, in this intermediate and unusual scale, converged both the interpretation of the urban pattern from the territorial point of view and the set of planning tools, articulated for scales and targets. From our analysis, some conclusions emerge:

(1) The close geography, which in Valladolid is supra-municipal and cross-provincial, defines the "basin of life and employment" with a specific dynamics. Those are explicable just from the local ecology point of view, which is subregional in scale and an urban-rural-natural mosaic in profile;

(2) We are looking for, in a closer geographical context, the rules which define the relationship between the city and its urban area: like real constraints (the landscape features, the E80 motorway, the Duero's corridor and other infrastructures), and like opportunities in connection with the region development we move from. The analysis moves from the conventional fields of research (centred in the central city and its 1 st and 2nd crown) and their quantitative approaches to a qualitative reading of the territory, based on the functional relationships between the city and other urban poles, including another spaces (the physical dimension in contrast with the limits of the statistical approach);

(3) In Valladolid, there is a singular coexistence between the classical model of an urban area and the emerging model of a "metropolizated" territory. The new geography of centrality depends on the tension between these two patterns;

(4) In this area, the location of both logistical and industrial functions keeps a large inertia, in relation to major transport flows - the corridor. Meanwhile, the residence, influenced by an opportunistic logic of "quality \& price", moves in a larger territory, beyond the polarity of central city. This tendency creates an emerging metropolitan area, different from the current 


\section{Strengthening of the Territorial Position of Valladolid through Planning Strategies: Networks, Patterns and Centralities}

administrative model.

\section{References}

[1] J. Garreau, Edge City: Life on the New Frontier, Doubleday, New York, USA, 1991.

[2] F. Ascher, Métapolis or the Future of Cities, Ed. Odile Jacob, Paris, France, 1995.

[3] F.J. Monclús, The Dispersed city: Suburbanization and New Peripheries, Centre of Contemporary Culture of Barcelona Ed., Barcelona, Spain, 1998.

[4] S. Graham, S. Marvin, Splintering Urbanism: Networked Infrastructures, Technological Mobilities and the Urban Condition. Routledge, London, England, 2001.

[5] A. Amin, N. Thrift, Cities: Reimagining the Urban, Polity, Cambridge, England, 2002.

[6] O. Nello, City of Cities, Milenio Ed., Lleida, Spain, 2002.

[7] A. Bagnasco, Society out of Square: How Is Changing Social Organization, Il Mulino, Bologna, Italy, 2003.

[8] F. Indovina, The metropolisation of territory: New territorial hierarchies, in: A. Font et al. (Eds.), The Explosion of the City, Ministry of Housing, Madrid, Spain, 2007.

[9] N. Portas, A. Domingues, J. Cabral, Urban Politics II: Transformations, Regulation and Projects, Calouste Gulbenkian Foundation, Lisboa, Portugal, 2011.

[10] European Union, Growth, Competitiveness, Employment-The Challenges and Ways forward into the 21st Century, European Union Regional Policy, Brussels, Belgium, 1993.

[11] EU (European Union), State of European Cities Report: Adding Value to the European Urban Audit, European Union Regional Policy, Brussels, Belgium, 2007.

[12] J.L. De las Rivas, Cities of Castle and Leon-Report, Castle and Leon Regional Council Ed., Valladolid, Spain, 2010.

[13] European Union, White Paper: Roadmap to a Single European Transport Area-Towards a Competitive and Resource Efficient Transport System, European Union Regional Policy, Brussels, Belgium, 2011.

[14] J.L. De las Rivas, Planning metropolitan processes, territorial guidelines for Valladolid and its outskirts, in: L. Galiana, and J. Vinuesa (Eds.), Theory and Practice for a Rational Territorial Planning, Editorial Síntesis S.A., Madird, Spain, 2010.

[15] B. Secchi, First Lesson of Urbanism, Laterza, Roma, Italy, 2000.

[16] A. Font, The explosion of the city, an international University research project, in: A. Font (Eds.), The Explosion of the City, Ministry of Housing, Madrid, Spain, 2007.

[17] J.L. De las Rivas, A. Calvo, S. Cortés, Industrial competitiveness and urban environment: The case of Valladolid, Ciudad y Territorio-Estudios Territoriales 106 (1995) 793-824.

[18] J.L. De las Rivas, Report-Territorial Guidelines for Valladolid and Its Outskirts. Environment and Planning Office-Castilla y León Regional Council Ed., Valladolid, Spain, 1998

[19] A. Álvarez, The Castilla Canal: A live Infrastructure who serves a territory, in: A. Álvarez, J.L. De las Rivas, F. Jubete, P. Fernández, J. Arribas, F. Roldán, The Castilla Canal: A Regional Plan. Ed. Cedexcehopu, Salamanca, Spain, 2004.

[20] J.L. De las Rivas, A. Álvarez, M. Paris, The industrial corridor Valladolid-Palencia: An emerging conurbation between two consolidated urban poles, Ciudad $\mathrm{y}$ Territorio-Estudios Territoriales, 176 (2013) 363-378.

[21] H. Pascual, The meaning of the industry and of the new infrastructures in the territorial pattern, in: J.M. Delgado (Ed.), Population and Settlemen in Castilla y León, Consejo Económico y Social de Castilla y León, Valladolid, Spain, 2012.

[22] CyL Económica, The 5,000 Most Important Companies in Castilla y León, Ediciones La Meseta S.L., Valladolid, Spain, 2012.

[23] Junta de Castilla y León, Decree 21/2010 approbation for the regional plan for the Duero Valley area, BOECYL (Boletìn Oficial de Castilla y Leon) 104 (2010) 44235-359.

[24] J. García, Valladolid, from the City to the Agglomeration, Editoral Ariel, Barcelona, Spain, 2000.

[25] R.T.T. Forman, Land Mosaic for the Barcelona Metropolitan Region, Editorial Gustavo Gili, Barcelona, Spain, 2004.

[26] R.T.T. Forman, Land Mosaics: The Ecology of Landscapes and Regions. Cambridge University Press, Cambridge, USA, 1995.

[27] F.R. Steiner, The Living Landscape: An Ecological Approach to Landscape Planning, Island Press, Washington D.C., USA, 2008.

[28] M. Paris, From city centres to centrality places: A methodological proposal, Ciudades 16 (2013) 47-69.

[29] M. Paris, Urbanism of Superplaces. Maggioli Editore, Rimini, Italy, 2009.

[30] Instituto Universitario de Urbanistica official website: http://www.uva.es/iuu/ (accessed August 7th, 2014).

[31] Territorial Guidelines for Valladolid and Its Outskirts Revision $2010 \quad$ [Online], http://bit.ly/10caWc9 (accessed August 7th, 2014).

[32] PGOU Valladolid Local Plan, Avance 2012[Online], http://bit.ly/X3iikz (accessed August 7th, 2014).

[33] J.L. De las Rivas, M. Paris, Valladolid as a crossroad of landscapes, Monograph Research 5 (2013) 84-87. 